Abstract ID: 99

\title{
A temporal analysis of maternal deaths in some selected health facilities in Zamfara State, Northwest Nigeria: How far were United Nations Millennium Development Goals (MDG) 5 achieved?
}

\author{
Abdullahi Mohammed Maiwada ${ }^{a}$ | Nor Azlina A Rahman ${ }^{a}$ | Suzanah Abdul Rahman ${ }^{\mathrm{a}}$ | Nik Mazlan \\ Mamat $^{\mathrm{a}}$ | Tukur A Baba ${ }^{\mathrm{b}}$ | Danladi Abubakar ${ }^{\mathrm{C}}$ \\ ${ }^{a}$ Kulliyah of Allied Health Sciences, International Islamic University Malaysia \\ ${ }^{b}$ Usmaun Danfodiyo University, Sokoto Nigeria \\ ${ }^{c}$ Federal Medical Center Gusau, Nigeria
}

Introduction: The steady increase in maternal deaths in Nigeria is a serious source of concern to policy makers and key stakeholders as one of the major threats to the achievement of the MDGs. Nigeria is reported to have one of the highest maternal mortality ratios in the world. This study was aimed at examining the challenges confronting the achievement of the MDGs Goals 5 in Zamfara State northwest Nigeria in terms of maternal mortality ratio, causes and frequency of antenatal visits. Methods: Health facility based approach and statistics were used in assessing maternal mortality ratio. Data was collected from health facility records and folders of patients who lost their lives due to pregnancy and childbirth related illnesses in some selected health facilities in Zamfara State from 2011- 2015. Results: The results showed the highest maternal deaths are in the rural areas 5120/100,000 as compared to $750 / 100,000$ urban health facilities. Haemorrhage was the leading medical cause of maternal death. Others include sepsis, eclampsia, sickle cell anaemia, obstructed labour and abortion. However, there was a significant increase in the number of antenatal care visits from $7.20 \%$ to $30.93 \%$ within the last five years. However, the maternal mortality rate has increased, though not stable from $735 / 100,000$ in 2011 to $1248 / 100,000$ in 2013 and 930/100,000 in mid-2015. Conclusions: There was an increase in maternal deaths in rural compared to urban areas health clinics despite increased in the attendance of ante natal care visits thus the $5^{\text {th }}$ Millennium Development Goal in Zamfara State not achieved.

KEYWORDS: Maternal deaths, maternal mortality, MDGs-4, Antenatal care, Zamfara State 